\title{
Parking Lot Test: Fact or Fiction!
}

To the Editor:

Many practitioners have been known to use the "Parking Lot Test" in accessing the veracity of their patient's axial spine complaints and functional disability. This usually involves observing the patient without his or her knowledge and comparing the amount of visible antalgia to that seen in the office. In the alternative, serial observations of the patient are used during the exam to determine if the patient is presenting in a consistent fashion. For instance, serial observations of range of motion while performing various tests are used to determine if the patient is consciously or unconsciously giving a false effort.

I recently had the opportunity to test this theory in a canine model. My dog has had a persistent limp for years and has an antalgic gait. The other night I was struck by a curious observation. When she came into the house, she was limping quite severely. Then in the space of a few seconds, when called, the limping decreased sharp- ly. Then after I had decided to give her a treat, the limp all but disappeared in her excitement. Had I uncovered an animal model of malingering? While I'd love to believe this, there is a much more scientific explanation. The most completely described pain modulating circuit includes the amygdala, PAG, DLPT and RVM in the brainstem (1). Through descending projections, this circuit controls both spinal and trigeminal dorsal horn pain transmission neurons. Several different neurotransmitters exert bi-directional control of pain through On cells that facilitate and Off cells that inhibit dorsal horn nociceptive neurons. Such an effect provides a physiological mechanism for the pain enhancing actions of mood, attention and expectation. So when my dog is expecting a steak, she stimulates her "Off" cells through descending influences from the amygdala, PAG, DLPT and RVM in the brainstem. This results in inhibition of nociceptive neurons in the dorsal horn and allows her to get to the steak much faster.

In summary, my animal model of malingering is nothing more than a biologic imperative that has evolved to make sure that we can modulate pain to achieve an important task. So the next time you apply the "Parking Lot Test", remember that observations of rapidly altering levels of antalgia or range of motion may just mean the patient is happy to leave your office.

\section{REFERENCES}

1. Fields HL. Pain modulation: Expectation, opioid analgesia and virtual pain. Prog Brain Res 2000; 122:245-253

\section{Christopher J. Centeno, M.D.}

Spinal Injury Foundation

11080 Circle Point Road, Suite 140

Westminster CO 80020

Email:

centenooffice@centenoclinic.com 